\title{
The effects of some phosphodiesterase inhibitors on the conductance of the perfused vascular beds of the chloralosed cat
}

\author{
T. C. HAMILTON
}

Pharmacology Department, Roche Products Ltd., Welwyn Garden City

\section{Summary}

1. The vasoactivity of a number of phosphodiesterase inhibitors in the autoperfused splanchnic region and hindquarters of the cat have been investigated.

2. Theophylline, dipyridamole and 4-(3,4-dimethoxybenzyl)-2-imidazolidinone (Ro 7-2956) and its analogues were more potent vasodilators in the splanchnic region than in the hindquarters, whereas papaverine was a potent vasodilator in both these vascular beds.

3. The vasodilator response to the phosphodiesterase inhibitors in the splanchnic region and hindquarters was not susceptible to $\beta$-adrenoceptor blockade.

4. Infusion of dibutyryl cyclic AMP into the superior mesenteric artery increased vascular conductance of the splanchnic region. This effect was enhanced by Ro 20-1724 in doses below those in which this compound affected conductance.

5. These results are consistent with the hypothesis that accumulation of cyclic AMP in vascular smooth muscle mediates the vasodilator response to phosphodiesterase inhibitors.

\section{Introduction}

By inhibition of the enzyme phosphodiesterase, which is responsible for the breakdown of cyclic 3',5'-AMP to 5'-AMP, papaverine, theophylline, dipyridamole and the imidazolidinones increase the intracellular level of cyclic AMP (Kukovetz, Poch \& Juan, 1969 ; Butcher \& Sutherland, 1962 ; Dalton, Quinn, Burghardt \& Sheppard, 1970 ; Sheppard \& Wiggan, 1971a \& b). The positive inotropic effect of these inhibitors, which persists in the presence of $\beta$-adrenoceptor blockade, may be related to the accumulation of cyclic AMP in cardiac muscle although the precise connexion between the metabolic and mechanical effects is undefined (Kukovetz \& Poch, 1970 ; Osborne, Wenger \& Moe, 1971).

Similarly the response of vascular smooth muscle to phosphodiesterase inhibitors may be related to their effect on intracellular levels of cyclic AMP. The studies of Bartelstone \& Nasmyth (1963), and of Bartelstone, Nasmyth \& Telford (1967), indicated that vasoconstrictors increased the level of cyclic AMP although Robison \& Sutherland (1970) claimed the converse to be the case, and Triner, Vulliemoz, Schwartz \& Nahas (1970) and Volicier \& Hynie (1971) showed that vasodilatation was associated with an accumulation of cyclic AMP. 
In the present study the hypothesis that cyclic AMP mediates vasodilatation has been examined, by indirect means, by measuring the vasodilator activity of a number of analogues of 4-(3,4-dimethoxybenzyl)-2-imidazolidinone (Ro 7-2956) in the perfused hindquarters and splanchnic region of the cat. In addition the effects of papaverine, theophylline, dipyridamole and of cyclic AMP and its dibutyryl derivative have been examined on the vasculature of these beds.

\section{Methods}

Cats of either sex were anaesthetized with chloralose, $100 \mathrm{mg} / \mathrm{kg}$ intraperitoneally. Systemic blood pressure was recorded from a carotid artery and heart rate was monitored.

The method of continuous and simultaneous measurement of blood flow, perfusion pressure and vascular conductance in either the autoperfused hindquarters or splanchnic region has been described previously (Gardiner, Hamilton \& Parkes, 1971). Blood flow was measured by an electromagnetic flow meter, using an extracorporeal flow probe, interposed in the abdominal aorta or superior mesenteric artery; perfusion pressure was measured distal to the flow probe. A continuous record of vascular conductance was obtained by electronic division of flow by pressure.

Saline $(0.9 \% \mathrm{NaCl}$, w/v) containing heparin (to give $5 \mathrm{mg} / \mathrm{kg}$ ) was injected intravenously immediately the cannulations were completed. Arterial injections were made via a side branch in the perfusion circuit, in a volume of 0.1 or $0.2 \mathrm{ml}$, and washed into the blood-stream with $0.1 \mathrm{ml}$ saline.

Drugs used were adenosine $5^{\prime}$ monophosphate (B.D.H.), adenosine cyclic $3^{\prime}, 5^{\prime}$, monophosphate (Boehringer Mannheim \& Sigma), $\mathrm{N}^{6}-2^{\prime}-O$-dibutyryl-3',5'-cyclic adenosine monophosphate (Boehringer Mannheim), dipyridamole (Boehringer Ingelheim), papaverine hydrochloride (McFarlane Smith), $( \pm)$-propranolol hydroshloride (I.C.I.) and theophylline (May \& Baker).

Ro 7-2956 and its analogues were synthesized by Dr. M. Hoffer, Hoffmann-La Roche, Nutley (Table 1).

Drugs were dissolved in saline and their doses are expressed as the base.

\section{Results}

\section{Changes in vascular conductance}

Intra-arterial injection of vasodilators, for example acetylcholine and isoprenaline, in the hindquarters and splanchnic region of the cat produced a dose-dependent increase in vascular conductance with a concomitant increase of blood flow and decrease in perfusion pressure. Vasoconstrictors produced the converse effects.

\section{Hindquarters}

Ro 20-1937, Ro 20-1977 and Ro 20-1779 were inactive as vasodilators in doses up to $2 \mathrm{mg}$. Ro 7-2956, Ro 20-1724, Ro 20-2926, Ro 20-3760, Ro 20-0419, theophylline and dipyridamole produced slight, though not consistent, vasodilatation which persisted for up to $5 \mathrm{~min}$ with doses greater than $200 \mu \mathrm{g}$. Papaverine, 10-200 $\mu \mathrm{g}$, produced dose-dependent vasodilatation which persisted for 30 seconds. 
TABLE 1. Structure of 4-(3,4-dimethoxybenzyl)-2-imidazolidinone (Ro 7-2956) and its analogues<smiles>O=C1CC(Cc2ccccc2)NCN1</smiles>

Compound

Ro 7-2956

Ro 20-0419

Ro 20-1724

Ro 20-3760

Ro 20-1937

Ro 20-2926

Ro 20-1977

Ro 20-1779

Theophylline

Papaverine
Substituent at position

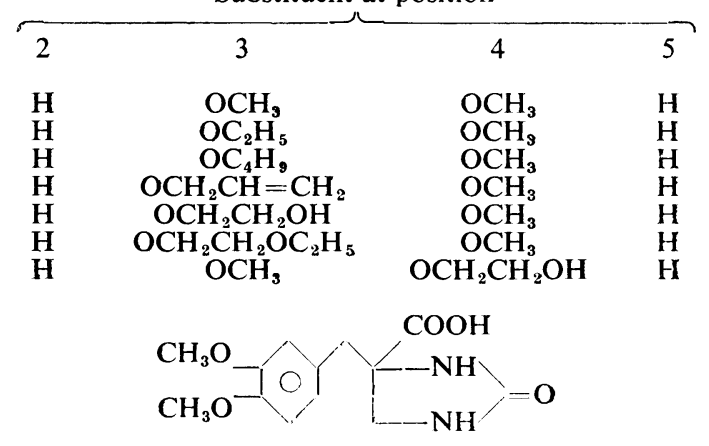

I50 ( $\mu \mathrm{M})$ (Sheppard \& Wiggan 1971a \& b)

12
$0 \cdot 7$
$0 \cdot 1$
$0.7 *$
9
$0.7 \%$
24

6,800

500

* H. Sheppard \& G. Wiggan (personal communication). The I50 is the concentration of drug producing a $50 \%$ inhibition of the hydrolysis of cyclic AMP by rat erythrocyte phosphodiesterase.

Cyclic AMP was inactive in doses up to $2 \mathrm{mg}$ in three initial experiments but the same substance tested 12 months later, and cyclic AMP obtained from another source (Sigma), produced vasodilatation in doses greater than $500 \mu \mathrm{g}$. Dibutyryl cyclic AMP, in doses up to $2 \mathrm{mg}$, was without effect in preparations where cyclic AMP was active.

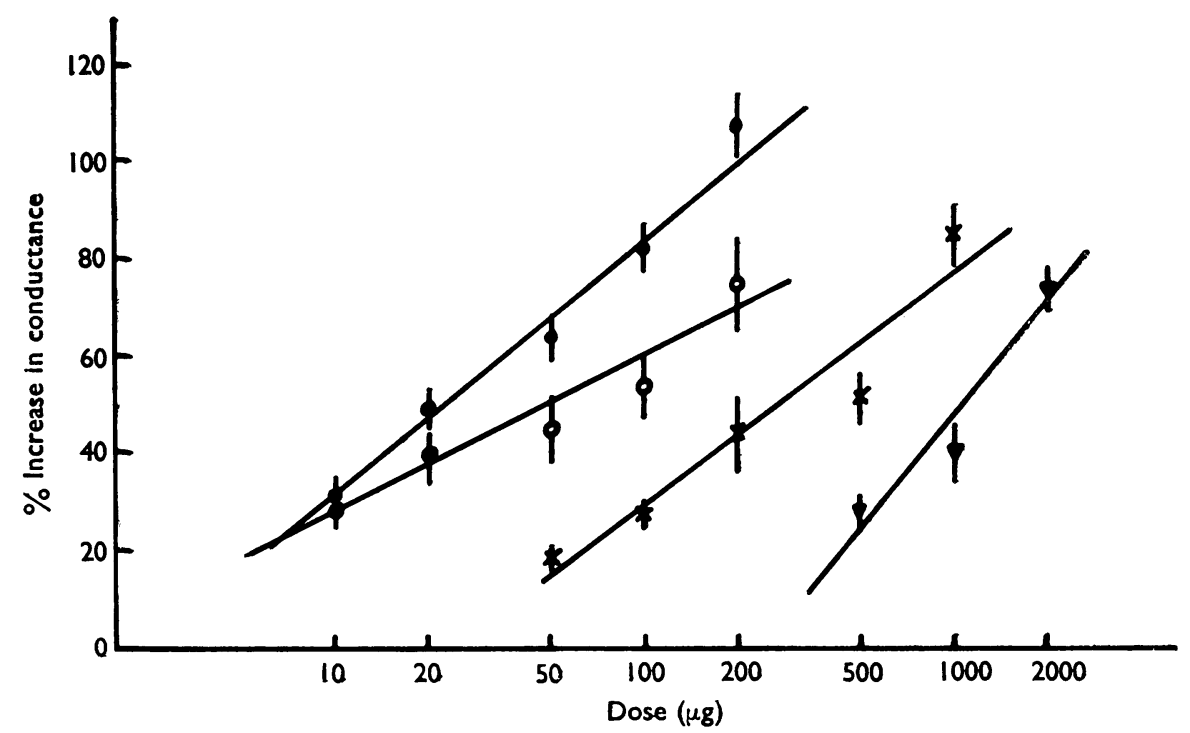

FIG. I. Relationship with dose of the per cent increase in conductance produced by papaverine (O), Ro 20-1724 (O), theophylline $(\times)$ and Ro 20-1977 ( $\nabla$ ) injected intraarterially in the autoperfused splanchnic region of the cat. Regression lines are computed (see Table 2). Vertical bars indicate \pm S.E.M. 
TABLE 2. Activity of some phosphodiesterase inhibitors as vasodilators in the splanchnic region

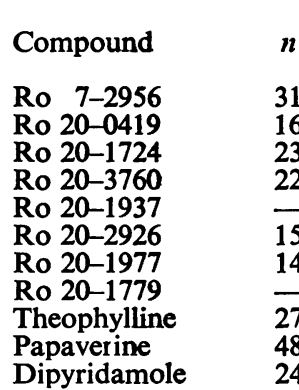

Slope (b) \pm standard error of the slope (Sb)
$43.81 \pm 5.75$
$37.56 \pm 8.73$
$32 \cdot 12 \pm 6 \cdot 31$
$21.1 \pm 5.93$
$30.3 \overline{ \pm} 9.62$
$77 \cdot 45 \pm 10 \cdot 8$
$47.69 \overline{ \pm} 4.97$
$54.83 \pm 4.46$
$33.6 \pm 3.4$

Dose ( $\mu$ g i.a.) to produce $50 \%$ increase in conductance

$\begin{aligned} 124 \cdot 4 & (86-182 \cdot 8) \\ 40 \cdot 8 & (21 \cdot 1-73 \cdot 3) \\ 47 \cdot 8 & (29 \cdot 3-79 \cdot 8) \\ 36 \cdot 8 & (7 \cdot 2-77 \cdot 4) \\ & >250 \cdot 0 \\ 361 \cdot 7 & (107 \cdot 4-999 \cdot 7) \\ 1,097 & (928-1,336) \\ 279 \cdot 4 & >2,000 \\ 22.5 & (18 \cdot 1-8-362 \cdot 1) \\ 117 \cdot 8 & (89 \cdot 7-170)\end{aligned}$

$n$ is the number of values used to calculate each regression line. The figures in parentheses are the $95 \%$ fiducial limits from the calculated dose-response regression lines.

\section{Splanchnic region}

Ro 20-1779 was inactive in doses up to $2 \mathrm{mg}$ while Ro 20-1937 produced inconsistent and prolonged vasodilatation in doses greater than $250 \mu \mathrm{g}$.

The other imidazolidinones, theophylline, dipyridamole and papaverine produced dose-dependent vasodilatation (Table 2 \& Fig. 1). The slopes of the calculated dose-response lines for the active compounds were not all parallel with each other. Comparison of the doses producing $50 \%$ increase in vascular conductance (Table 2) for each compound does not therefore provide a valid relative potency in every instance. However, certain conclusions may be deduced from the relative activities appearing: papaverine was approximately twice as potent as Ro 20-0419, six times as potent as Ro 7-2956, fifty times as potent as Ro 20-1977 and twelve times as potent as theophylline. Dipyridamole was 2.5 times as potent as theophylline and was equiactive with Ro 7-2956.

The dilator responses to papaverine, theophylline and dipyridamole persisted for 30 seconds. In contrast, those to the imidazolidinones, after an initial peak effect, showed a secondary and prolonged increase in conductance.

As in the hindquarters preparation, cyclic AMP was inactive in four initial experiments but active in subsequent ones, doses greater than $0.5 \mathrm{mg}$ producing increases in conductance. Dibutyryl cyclic AMP was inactive when injected in doses up to $2 \mathrm{mg}$, though arterial infusions of $500 \mu \mathrm{g} / \mathrm{min}$ for $15 \mathrm{~min}$ produced increased conductance (Fig. 2).

\section{Effects on heart rate and systemic blood pressure}

The arterial administration of a sufficiently large dose of Ro $20-0419(100 \mu \mathrm{g})$, Ro 20-1724 (100 $\mu \mathrm{g})$, Ro 20-2926 (1 mg), Ro 20-3760 (200 $\mu \mathrm{g}$ ), Ro 20-1937 (200 $\mu \mathrm{g})$ and Ro 7-2956 $(100 \mu \mathrm{g})$ resulted in sufficient of the drug escaping into the general circulation to produce short-lived decreases in blood pressure and prolonged tachycardia. Ro 20-1977 (2 mg) and Ro 20-1779 (2 mg) had no effect on these parameters.

\section{Effects of dipyridamole and Ro 20-1724 on the vasodilator response to $A M P$, cyclic $A M P$ and its dibutyryl derivative}

As described above, cyclic AMP was active only in some preparations. The possibility existed that AMP contaminated the sample. 


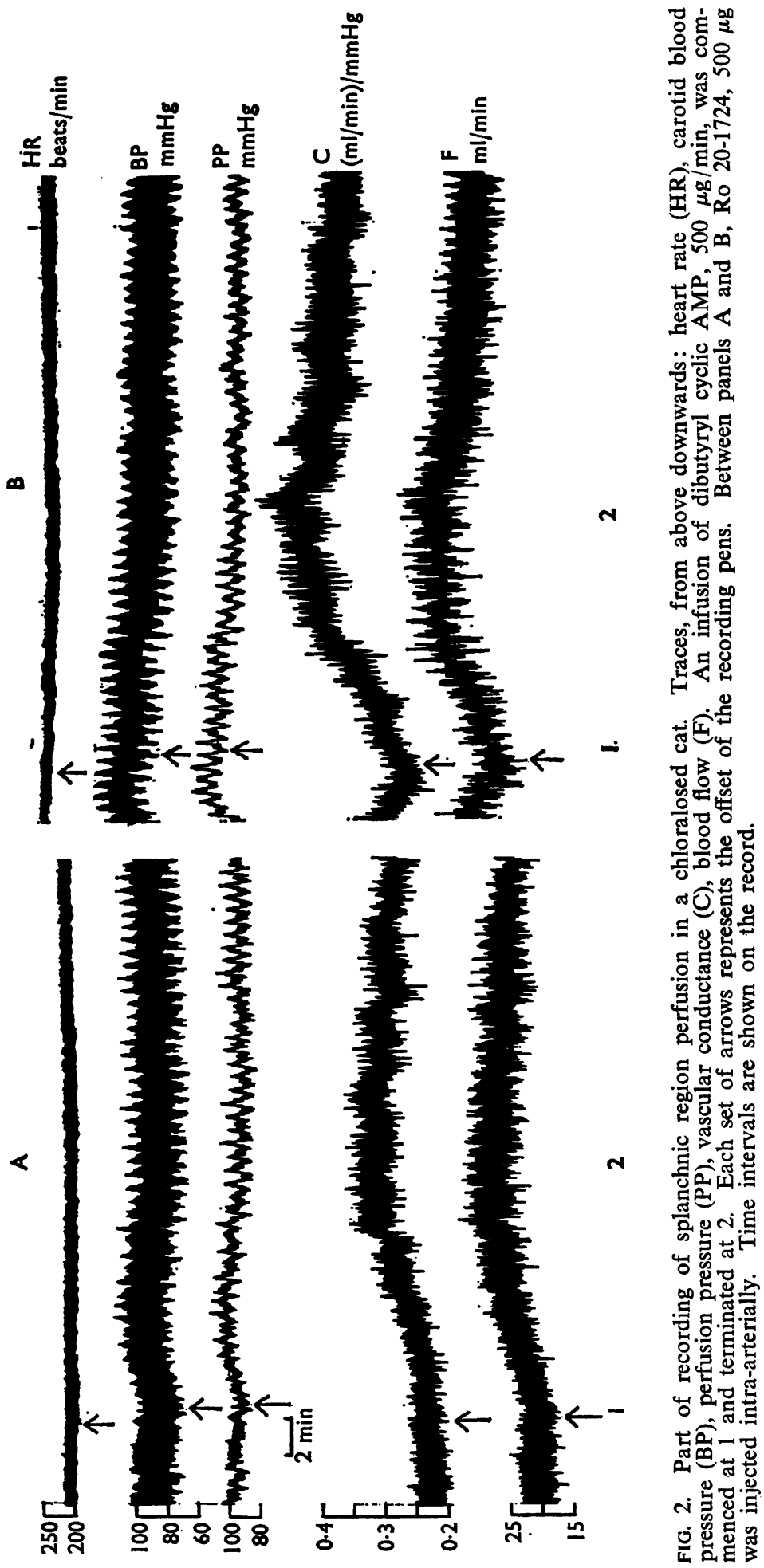


TABLE 3. Effect of dipyridamole, $1 \mathrm{mg} / \mathrm{kg}$ i.v. on the vasodilator responses to AMP and cyclic AMP in the splanchnic region
Compound of the slope (Sb)

AMP

After dipyridamole

Cyclic AMP

After dipyridamole
Slope (b) \pm standard error

$\begin{array}{rl}56 \cdot 66 & \pm 13 \cdot 35 \\ 56 \cdot 76 & 12 \cdot 67 \\ 83 \cdot 74 \pm 25 \cdot 0 & \\ 119 \cdot 36 \pm 18 \cdot 5\end{array}$

Dose ( $\mu$ g i.a.) to produce $50 \%$ increase in conductance

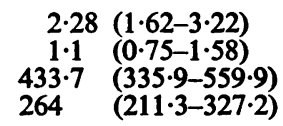

$n$ is the number of values used to calculate each regression line. The figures in parentheses are the $95 \%$ fiducial limits from the calculated dose-response regression lines.

TABLE 4. Effect of Ro 20-1724, $2 \mathrm{mg} / \mathrm{kg}$ i.v. on the vasodilator responses to AMP and cyclic AMP in the splanchnic region

\section{Compound}

AMP

After Ro 20-1724

Cyclic AMP

After Ro 20-1724
Slope (b) \pm standard error

$n$

13

13

10

10 of the slope (Sb)

$$
\begin{aligned}
& 67 \cdot 51 \pm 8 \cdot 18 \\
& 68 \cdot 06 \pm 7 \cdot 61 \\
& 84.92 \pm 14 \cdot 63 \\
& 80 \cdot 21 \pm 15 \cdot 46
\end{aligned}
$$

Dose ( $\mu$ g i.a.) to produce $50 \%$ increase in conductance

$$
\begin{gathered}
2 \cdot 1(1 \cdot 58-2 \cdot 71) \\
2 \cdot 1(1 \cdot 59-2 \cdot 66) \\
355.9(283 \cdot 4-444 \cdot 7) \\
349 \cdot 3(271 \cdot 4-449 \cdot 4)
\end{gathered}
$$

\begin{tabular}{|c|c|c|c|}
\hline Compound & $n$ & $\begin{array}{c}\text { Slope (b) } \pm \text { standard error } \\
\text { of the slope (Sb) }\end{array}$ & $\begin{array}{l}\text { Dose ( } \mu \mathrm{g} \text { i.a.) to prod } \\
50 \% \text { increase in conduc }\end{array}$ \\
\hline $\begin{array}{l}\text { Before propranolol } \\
\text { After } 1 \mathrm{mg} \text { propranolol }\end{array}$ & $\begin{array}{l}12 \\
12\end{array}$ & $\begin{array}{l}52 \cdot 48 \pm 18 \cdot 57 \\
47.92 \pm 16 \cdot 10\end{array}$ & $\begin{array}{l}32 \cdot 6(10 \cdot 5-98 \cdot 3) \\
34 \cdot 3(13 \cdot 4-96 \cdot 6)\end{array}$ \\
\hline
\end{tabular}

$n$ is the number of values used to calculate each regression line. The figures in parentheses are the $95 \%$ fiducial limits from the calculated dose-response regression lines.

TABLE 5. Effect of propranolol, $1 \mathrm{mg}$ intra-arterially, on the vasodilator response to papaverine in the splanchnic region

$n$ is the number of values used to calculate each regression line. The figures in parentheses are the $95 \%$ fiducial limits from the calculated dose-response regression lines.

Dipyridamole has been shown to potentiate the vasodilator effects of the adenine nucleotides (Kontos, Goldin, Richardson \& Patterson, 1968). Table 3 shows that dipyridamole, $1 \mathrm{mg} / \mathrm{kg}$, i.v., potentiated the vasodilator effect of AMP and that of cyclic AMP in the splanchnic region.

However, Ro 20-1724, $2 \mathrm{mg} / \mathrm{kg}$, i.v., did not alter the vasodilator effects of AMP or those of cyclic AMP (Table 4). Although dibutyryl cyclic AMP, $2 \mathrm{mg}$, was inactive following the administration of cumulative doses of Ro 7-2956, Ro 1937 and Ro 20-1724, the increase of conductance produced by the infusion of dibutyryl cyclic AMP, $500 \mu \mathrm{g} / \mathrm{min}$ into the superior mesenteric artery, was potentiated by Ro 20-1724, $500 \mu \mathrm{g}$ arterially (Fig. 2).

\section{Effects of $\beta$-adrenoceptor blockade}

In doses greater than those required to antagonize the vasodilator response of isoprenaline, propranolol, $1 \mathrm{mg}$ intra-arterially, did not affect the increase in splanchnic region or hindquarters conductance produced by Ro 7-2956, Ro 201724 or papaverine (Table 5). 


\section{Discussion}

Evidence derived from this study is consistent with the hypothesis that the accumulation of cyclic AMP leads to the relaxation of vascular smooth muscle, since the phosphodiesterase inhibitors tested were active as vasodilators by a mechanism not susceptible to $\beta$-adrenoceptor blockade. Moreover, vasodilatation was produced during arterial infusion of dibutyryl cyclic AMP.

Differences apparently exist in the reactivity of the two beds studied. Papaverine was the only compound producing dose-dependent dilatation in the hindquarters. The other compounds, with the exception of Ro 20-1779 and Ro 20-1937 which were inactive, produced slight vasodilatation but the minimum effective dose for this effect was up to twenty-five times more than that required for small increases in splanchnic region conductance. In the splanchnic bed, the active phosphodiesterase inhibitors produced dose-dependent increases in vascular conductance ; papaverine was approximately twelve times more active than theophylline and eight times more active than dipyridamole. Kukovetz \& Poch (1970) reported that phosphodiesterase extracted from beef coronary arteries was twenty-five times more sensitive to inhibition by papaverine than by theophylline, and three times more sensitive to papaverine than to dipyridamole, whereas Triner et al. (1970) found papaverine to be fifteen times more active than theophylline in inhibiting the enzyme obtained from rat aorta.

A close correlation existed for the imidazolidinones, between their I50 values for the inhibition of phosphodiesterase derived from rat red blood cells and their ability to lower the blood pressure of the hypertensive rat (Pettinger, Bautz, Wiggan \& Sheppard, 1970), and in the work described here correlation could also be shown with their vasodilator potency in the splanchnic region $(P<0.01)$. Although compounds most active in inhibiting the erythrocyte enzyme were potent vasodilators (Ro 20-3760, Ro 20-0419 and Ro 20-1724), and those reported to be weak inhibitors were inactive or showed only slight activity as vasodilators (Ro 20-1779 and Ro 20-1977) ; this relationship did not extend to all dilators tested.

Theophylline, which was 20 times less active than Ro 20-1977 and Ro 20-2926 as an inhibitor of the rat erythrocyte enzyme, was five times more active as a vasodilator in the splanchnic region. Ro 20-1937 which was slightly more active than Ro 7-2956 and 55 times more active than theophylline as an inhibitor of the erythrocyte phosphodiesterase, possessed negligible vasodilator activity compared with these compounds. In addition Ro 7-2956 and papaverine were equally active as inhibitors of this enzyme but papaverine was 5 times more active than the imidazolidinone as a splanchnic region vasodilator.

This spectrum of activity could be related to the substituents at positions 3 and 4 on the aromatic ring: elongation of the substituents at position 3 increased potency compared with Ro 7-2956 while elongation at position 4 or the introduction of a carboxyl group in the imidazolidinone ring yielded a weak inhibitor.

However, the presence of an oxygen-containing function on the ethoxy side chain at position three of the imidazolidinone ring in Ro 20-1937 and Ro 20-2926 markedly decreased vasodilator activity compared with inhibition of rat erythrocyte enzyme.

It is possible, however, that a more valid comparison of vasodilator activity with potency as phosphodiesterase inhibitors might be made if the enzyme con- 
cerned were to be derived from arterial smooth muscle. Sheppard \& Wiggan (1971b) have shown that the potency of phosphodiesterase inhibitors varies with the source of the enzyme.

The absence of a vasodilator response following the arterial injection of dibutyryl cyclic AMP was unexpected since cyclic AMP was active, despite its lower lipid solubility (Falbriard, Pasternak \& Sutherland, 1967). Hashimoto, Kumakura \& Tanemura (1964) reported that cyclic AMP increased canine femoral and coronary artery flow but constricted the renal artery. Imura, Matsukura, Matsuyama, Setsuda \& Miyake (1965) found that it decreased adrenal gland blood flow in the rat. However, in the cat splanchnic region, the vasodilator effect of cyclic AMP, and of AMP, was potentiated by dipyridamole, a drug which augments the effects of AMP by preventing the decomposition of adenosine produced by dephosphorylation of AMP (Bunag, Douglas, Imai \& Berne, 1964). Conversely, Ro 20-1724 did not modify these responses. These results suggest that dipyridamole potentiated the effect of cyclic AMP, not by virtue of its phosphodiesterase inhibitory properties, but by its effect on adenosine: the sample of cycle AMP might therefore have been contaminated with AMP.

Dibutyryl cyclic AMP has been reported to relax the isolated tracheal chain preparation, but only after a prolonged contact time (Moore, Iorio \& McManus, 1968). Although this compound was found inactive on injection of up to $2 \mathrm{mg}$, infusion into the superior mesenteric artery of the cat was found to increase vascular conductance, confirming the observations of other workers that this compound has an action on vascular smooth muscle ; moreover, this effect was enhanced by injection of Ro 20-1724. Isaksson, Hjalmarson \& Ahren (1970) reported that dibutyryl cyclic AMP increased coronary artery flow of the isolated, working rat heart; Demsey \& Stoclet (1971) found that it inhibited noradrenalineinduced contractions of isolated rat aortic strips; Imura et al. (1965) reported that it decreased adrenal gland blood flow ; both cyclic AMP and its dibutyryl derivative were reported to inhibit spontaneous activity of rat portal vein (Berti, Sirtori \& Usardi, 1970), whereas Berti, Bernareggi \& Mandelli (1971) found that while cyclic AMP increased the tone of the isolated rat caudal artery, dibutyryl cyclic AMP induced relaxation.

The relaxation and contraction process of vascular smooth muscle has not been fully elucidated (Somlyo \& Somlyo, 1968 ; Mellander \& Johansson, 1968) but it is probable that cyclic AMP is involved (Triner et al., 1970; Volicier \& Hynie, 1971). As suggested by the activities found in this study, the phosphodiesterase in different arteries may vary and hence drugs acting in this manner may be more effective in some vascular beds than in others.

I am indebted to Dr. M. W. Parkes for his criticism of the work and helpful discussion in the preparation of the manuscript.

REFERENCES

Bartelstone, H. J. \& NASMyth, P. A. (1963). Possible implication of adenosine-3'5' $5^{\prime}$-phosphate in vascular responses produced by vasopressin and catecholamines. Fedn Proc., 22, 541.

BARTELSTONe, H. J., NASMYTH, P. A. \& TeLFORD, J. M. (1967). The significance of adenosine cyclic 3'5'-monophosphate for the contraction of smooth muscle. J. Physiol., Lond., 188, 159-176.

Berti, F., BernAREGGI, V. \& MANDELLI, V. (1971). Contraction and relaxation of in vitro perfused rat caudal artery: a possible role for cyclic $3^{\prime} 5^{\prime}$-AMP. Arch. int. Pharmacodyn. Thér., 192, 247-254. 
Berti, F., Sirtori, C. \& Usardi, M. M. (1970). Cyclic 3'5'-AMP, its dibutyryl derivative and theophylline effects on the rat portal vein in vitro. Arch. int. Pharmacodyn. Therr., 184, 328-333.

Bunag, R. D., Douglas, C. R., Imai, S. \& Berne, R. M. (1964). Influence of a pyrimidopyrimidine derivative on deamination of adenosine by blood. Circulation Res., 15, 83-88.

Butcher, R. W. \& Sutherland, E. W. (1962). Adenosine 3'5'-phosphate in biological materials. I. Purification and properties of cyclic $3^{\prime} 5^{\prime}$-nucleotide phosphodiesterase and use of this enzyme to characterize adenosine $3^{\prime} 5^{\prime}$-phosphate in human urine. J. biol. Chem., 237, 1244-1250.

Dalton, C., QuinN, J. B., Burghardt, C. R. \& Sheppard, H. (1970). Investigation of the mechanism of action of the lipolytic agent 4-(3,4-dimethoxybenzyl)-2-imidazolidinone (Ro 7-2956). J. Pharmac. exp. Ther., 173, 270-276.

Demsey, F. \& Stoclet, J. C. (1971). On the mechanism of papaverine action on the control of vascular smooth muscle contractile activity by extracellular calcium. J. Pharm. Pharmac., 23, 712-713.

Falbriard, J. G., Pasternak, T. \& Sutherland, E. W. (1967). Preparation of derivatives of adenosine 3'5'-phosphate. Biochemica et Biophysica Acta (Amst.), 148, 99-105.

Gardiner, D., Hamilton, T. C. \& Parkes, M. W. (1971). A method for the continuous recording of vascular conductance. J. Pharm. Pharmac., 23, 765-769.

Hashimoto, K., Kumakura, S. \& Tanemura, I. (1964). Mode of action of adenine, uridine and cytidine nucleotides and 2,6-bis(diethanolamine)-4,8-dipiperidino-pyrimidino (5,4-d) pyrimidine on the coronary, renal and femoral arteries. Arzneimittel-Forschung, 14, 1252-1254.

Imura, H., Matsukura, S., Matsuyama, H., Setsuda, T. \& Miyake, T. (1965). Adrenal steroidogenic effect of adenosine $3^{\prime}, 5^{\prime}$-monophosphate and its derivatives in vivo. Endocrinology, 76, 933-937.

Isaksson, O., Hualmarson, A. \& Ahren, K. (1970). Effects of dibutyryl-3'5'-AMP on the isolated working rat heart. Acta Pharmac. Tox., 28, suppl. 1, 53.

Kontos, H. A., Goldin, D., Richardson, D. W. \& PatTerson, J. L. (1968). Effect of dipyridamole on vasodilator responses to ischemia, hypoxia, ATP and AMP. Amer.J. Physiol., 214, 108-114.

Kukovetz, W. R. \& Poch, G. (1970). Inhibition of cyclic-3'5'-nucleotide-phosphodiesterase as possible mode of action of papaverine and similarly acting drugs. Naunyn-Schmiedebergs. Arch. exp. Path. Pharmak., 267, 189-194.

Kukovetz, W. R., Poch, G. \& Juan, H. (1969). The role of phosphodiesterase inhibition in the mechanism of coronary dilatation by drugs. Abstracts of IVth International Congress on Pharmacology, Basle, p. 270.

Mellander, S. \& Johansson, B. (1968). Control of resistance, exchange and capacitance functions in the peripheral circulation. Pharmac. Rev., 20, 117-196.

Moore, P. F., Iorio, L. C. \& McMANUs, J. M. (1968). Relaxation of the guinea-pig tracheal chain preparation by $\mathrm{N}^{6} 2^{\prime}$-o-dibutyryl 3'5'-cyclic AMP. J. Pharm. Pharmac., 20, 368-372.

Osborne, M. W., Wenger, J. J., Moe, R. A. (1971). Hemodynamic effects of 4-(3,4-dimethoxybenzyl)-2-imidazolidinone (Ro 7-2956): a nonadrenergic myocardial stimulant. J. Pharmac. Exp. Ther., 176, 174-183.

Pettinger, W. A., Bautz, G. T., Wiggan, G. A. \& Sheppard, H. (1970). Cyclic AMP as a mediator of vasodilation: indirect evidence. Pharmacologist, 12, No. 2, 291.

Robison, G. A. \& Sutherland, E. W. (1970). Sympathin E, Sympathin I, and the intracellular level of cyclic AMP. Circulation Res., 27, Suppl. 1, 147-161.

Sheppard, H. \& WigGan, G. (1971a). Analogues of 4-(3,4-dimethoxybenzyl)-2-imidazolidinone as potent inhibitors of rat erythrocyte adenosine cyclic $3^{\prime}, 5^{\prime}$-phosphate phosphodiesterase. Molec. Pharmac., 7, 111-115.

Sheppard, H. \& Wiggan, G. (1971b). Different sensitivities of the phosphodiesterases of dog cerebral cortex and erythrocytes to inhibition by synthetic agents and cold. Biochem. Pharmac., 20, 2128-2130.

Sомцyo, A. P. \& Sомцyo, A. V. (1968). Vascular smooth muscle. I. Normal structure, pathology, biochemistry and biophysics. Pharmac. Rev., 20, 197-272.

Triner, L., Vulliemoz, Y., Schwartz, I. \& Nahas, G. G. (1970). Cyclic phosphodiesterase activity and the action of papaverine. Biochem. Biophys. Res. Com., 40, 64-69.

Volicier, L. \& HyNie, S. (1971). Effect of catecholamines and angiotensin on cyclic AMP in rat aorta and tail artery. Eur. J. Pharmac., 15, 214-220.

(Received June 23, 1972) 